\title{
MANEJO DA IRRIGAÇÃO NA CULTURA DO FEIJOEIRO EM SISTEMAS PLANTIO DIRETO E CONVENCIONAL ${ }^{1}$
}

\author{
LUIZ C. PAVANI ${ }^{2}$, ADRIANO S. LOPES ${ }^{3}$, RAFAEL B. GALBEIRO ${ }^{4}$
}

RESUMO: O manejo inadequado do solo e da água é limitante à produtividade do feijoeiro irrigado. O objetivo deste trabalho foi avaliar dois métodos de manejo da irrigação, um via solo (tensiometria) e outro via clima (tanque Classe A), conjugados com os sistemas plantio direto e convencional de manejo do solo com a cultura do feijoeiro de "inverno", no segundo ano de plantio direto, em Jaboticabal - SP. Foi medido o potencial mátrico do solo e estimada a variação diária do armazenamento de água no solo, na camada de 0 a $0,40 \mathrm{~m}$ de profundidade, e avaliados os componentes de produtividade, além de determinadas a evapotranspiração real média e a eficiência média de uso de água pela cultura. O sistema de preparo convencional do solo com manejo de irrigação pelo tanque Classe A proporcionou maior produtividade de grãos, evapotranspiração média e eficiência de uso de água pela cultura, seguido pelo plantio direto com manejo de irrigação por tensiometria e por tanque Classe A. O sistema plantio direto foi menos suscetível às variações hídricas no solo decorrentes dos manejos de irrigação empregados do que o sistema de preparo convencional, resultando em menor variação na produtividade de grãos.

PALAVRAS-CHAVE: Phaseolus vulgaris, evapotranspiração real, eficiência de uso de água.

\section{IRRIGATION MANAGEMENT IN DRY BEAN UNDER CONVENTIONAL AND NO TILLAGE SYSTEMS}

\begin{abstract}
The unsuitable soil and water management in irrigated bean crop is a limitant factor for the yield of this crop. The objective of this research was to compare the performance of two methods of irrigation management, one by soil (tensiometry) and another by climate (Class A pan), in conventional and no tillage systems on the irrigated dry bean winter crop in the second year of no tillage system in Jaboticabal - SP. It was evaluated; average number of pods, grains per pods, weight of 1000 grains, grain yield per hectare, soil humidity variation, real evapotranspiration and crop water use efficiency. It was concluded that the biggest grains yield, mean daily evapotranspiration and crop water use efficiency was found in the conventional tillage system irrigated by Class A pan, followed by the no tillage system irrigated by tensiometry and Class A pan. No tillage was less susceptible than conventional tillage to the water variability of the soil due irrigation water management method used, which also resulted in less yield variability.
\end{abstract}

KEYWORDS: Phaseolus vulgaris, real evapotranspiration, crop water use efficiency.

\section{INTRODUÇÃO}

Regiões do Estado de São Paulo em que, no período de outono-inverno, as condições de temperatura e de radiação solar são adequadas para a produção agrícola, mas é maior a probabilidade de ocorrência de déficit hídrico importante no solo, a adoção do sistema plantio direto e da irrigação por aspersão na cultura do feijoeiro constitui-se em boa opção de cultivo.

\footnotetext{
${ }^{1}$ Extraído da tese de doutorado do segundo autor.

${ }^{2}$ Eng ${ }^{\mathrm{o}}$ Agrônomo, Prof. Dr., Faculdade de Ciências Agrárias e Veterinárias de Jaboticabal (FCAV/UNESP), Departamento de Engenharia Rural, Fone: (0XX16) 32092637, lcpavani@fcav.unesp.br

3 Eng ${ }^{\circ}$ Agrônomo, Prof. Dr., Universidade Estadual de Mato Grosso do Sul (UEMS), Unidade Universitária de Aquidauana, lopes@uems.br.

${ }^{4}$ Engo ${ }^{\circ}$ Agrônomo, Faculdade de Ciências Agrárias e Veterinárias de Jaboticabal (FCAV/UNESP).

Recebido pelo Conselho Editorial em: 18-10-2006
}

Aprovado pelo Conselho Editorial em: 6-11-2007 
Métodos de manejo de irrigação que utilizam tensiômetros ou o tanque Classe A possibilitam a adoção da irrigação como técnica para o aumento da rentabilidade do sistema agrícola. De acordo com OLIVEIRA et al. (2000), a demanda total de água estimada para o feijoeiro, com base na evaporação do tanque Classe $\mathrm{A}$, é superior em $11 \%$ à demanda estimada por tensiometria em área manejada no sistema de preparo convencional do solo e em $29 \%$ em plantio direto. LOPES et al. (2004) ressaltam que o método de tensiometria possibilita melhor entendimento das reais condições hídricas do solo na região do sistema radicular da cultura por monitorar as variações diárias do potencial mátrico do solo e, indiretamente, a variação do armazenamento de água na zona radicular da cultura.

Com relação ao sistema de manejo do solo, STONE \& SILVEIRA (1999) relatam que a semeadura direta do feijoeiro irrigado por aspersão no inverno, na resteva da cultura anterior, vem tendo aceitação cada vez maior na região central do Brasil.

SILVEIRA \& STONE (2002) encontraram produtividades de $2.095 \mathrm{~kg} \mathrm{ha}^{-1}$ no sistema de preparo convencional com arado de aivecas, $2.252 \mathrm{~kg} \mathrm{ha}^{-1}$ com grade aradora e $2.082 \mathrm{~kg} \mathrm{ha}^{-1}$ no sistema plantio direto. KLUTHCOUSKI et al. (2000) obtiveram maior produtividade de grãos de feijão no sistema plantio convencional do que no plantio direto durante oito anos.

Para SILVA et al. (2004b), diferentes tipos de preparo do solo na cultura do feijoeiro irrigado, no inverno, por três anos, não proporcionaram diferenças quanto à produtividade de grãos, embora o cultivo mínimo tenha-se sobressaído nos dois primeiros anos e obtiveram como média de produtividade para os três anos, $1.972 \mathrm{~kg} \mathrm{ha}^{-1}$ para o sistema plantio direto e $2.084 \mathrm{~kg} \mathrm{ha}^{-1}$ para o preparo convencional do solo.

O objetivo do trabalho foi comparar dois métodos de manejo da irrigação (tensiometria e tanque Classe A), na cultura do feijoeiro, em área irrigada por pivô central, conjugados com dois sistemas de manejo do solo (plantio direto e convencional).

\section{MATERIAL E MÉTODOS}

O experimento foi instalado no município de Jaboticabal - SP, cujas coordenadas geográficas são $21^{\circ} 14^{\prime} 48^{\prime \prime}$ de latitude sul, $48^{\circ} 16^{\prime} 44^{\prime \prime}$ de longitude oeste e altitude média de $557 \mathrm{~m}$. A declividade média da área experimental é de $6 \%$, e o solo é um Latossolo Vermelho eutroférrico (EMBRAPA, 1999).

As normais climatológicas do município, como valores médios anuais do período de 1971 a 2000, são: $1.424,6 \mathrm{~mm}$ de chuva; $943,5 \mathrm{hPa}$ de pressão atmosférica; $28,9{ }^{\circ} \mathrm{C}, 16,8{ }^{\circ} \mathrm{C}$ e $22,2{ }^{\circ} \mathrm{C}$ de temperaturas máximas, mínima e média do ar, respectivamente; $70,8 \%$ de umidade relativa do ar; insolação total de $2.585,8 \mathrm{~h}$ e total de 117,5 dias com chuva (ESTAÇÃO AGROCLIMATOLÓGICA, 2003).

A cultura do feijoeiro foi conduzida em 3,3 ha de área cultivada e irrigada com sistema pivô central, na qual foram demarcadas três parcelas de cada tratamento, cada uma com $11,25 \mathrm{~m}^{2}$ de área total e $5,54 \mathrm{~m}^{2}$ de área útil. A uniformidade de aplicação de água e as lâminas médias aplicadas às velocidades proporcionais de rotação da última torre do pivô de $20 \%, 50 \%$ e $100 \%$, foram avaliadas antes da instalação das parcelas experimentais, segundo os procedimentos descritos em SILVEIRA \& STONE (1994), ABNT (1998) e DOURADO NETO \& FANCELLI (2000).

O delineamento experimental utilizado foi o de blocos casualizados, em fatorial $2 \times 2$, composto por três blocos, com três parcelas de cada tratamento em cada bloco (BANZATO \& KRONKA, 1989), sendo os resultados analisados por meio do teste de Tukey $(\mathrm{P}<0,05)$. Os tratamentos foram dois métodos de manejo de irrigação e dois sistemas de manejo do solo assim descritos: manejo da irrigação por tensiometria (Tens) e pelo tanque Classe A (TCA); sistema de preparo convencional do solo (PC), em que foram realizadas duas gradagens pesadas (préincorporação e incorporação dos restos culturais) e uma gradagem leve para a eliminação de torrões e incorporação de herbicida pré-plantio (trifluralina), e sistema plantio direto (PD), em que foi 
aplicado herbicida dessecante um dia antes da semeadura. $\mathrm{O}$ experimento foi conduzido no segundo ano de implantação do sistema plantio direto. A quantidade de palha na superfície do solo antes da semeadura do feijoeiro estava em torno de $6 \mathrm{tha}^{-1}$.

A área foi conduzida desde novembro de 2001 com a cultura do milho no verão e a do feijoeiro no inverno. Após a colheita do milho, em março de 2003, preparo do solo no sistema convencional e aplicação de herbicida glyphosato antes da semeadura $\left(5,0 \mathrm{~L} \mathrm{ha}^{-1}\right)$ no plantio direto, realizou-se a semeadura do feijoeiro (Phaseolus vulgaris L.), cultivar IAC-Carioca, a qual ocorreu em 2-7-2003. Na semeadura, a adubação aplicada foi de $214 \mathrm{~kg} \mathrm{ha}^{-1}$ da formulação 10-20-20 (N$\mathrm{P}_{2} \mathrm{O}_{5}-\mathrm{K}_{2} \mathrm{O}$ ), baseada na análise química do solo, e a adubação de cobertura foi realizada aos 30 dias após a semeadura, utilizando-se de nitrato de amônio (75 $\left.\mathrm{kg} \mathrm{ha}^{-1} \mathrm{de} \mathrm{N}\right)$. Foram aplicados inseticidas para o controle preventivo da mosca-branca (Bemisia tabaci) e da vaquinha (Diabrotica speciosa). Também foi aplicado herbicida seletivo para a cultura do feijoeiro. A colheita das parcelas foi realizada em 13-10-2003, aos 94 dias após a emergência (DAE).

A curva característica média de retenção de água no solo foi determinada para o perfil de 0 a 0,40 $\mathrm{m}$ de profundidade, considerada essa última a profundidade efetiva do sistema radicular da cultura (PIRES et al., 2001), utilizando-se da equação de GENUCHTEN (1980), como segue:

$$
\theta=\theta_{r}+\frac{\theta_{s}-\theta_{r}}{\left[1+(\alpha|\Psi m|)^{n}\right]^{m}}
$$

Os valores das constantes empíricas dessa equação e as demais características físico-hídricas do solo da área, como valores médios para a camada de 0 a $0,40 \mathrm{~m}$ de profundidade, estão apresentados na Tabela 1.

TABELA 1. Características físico-hídricas médias e constantes da equação de GENUCHTEN para a camada de 0 a $0,40 \mathrm{~m}$ de profundidade do solo da área experimental. Average physico-hidrical characteristics and constants of the GENUCHTEN equation for the soil layer from 0 to $0.40 \mathrm{~m}$ of depth at the experimental site.

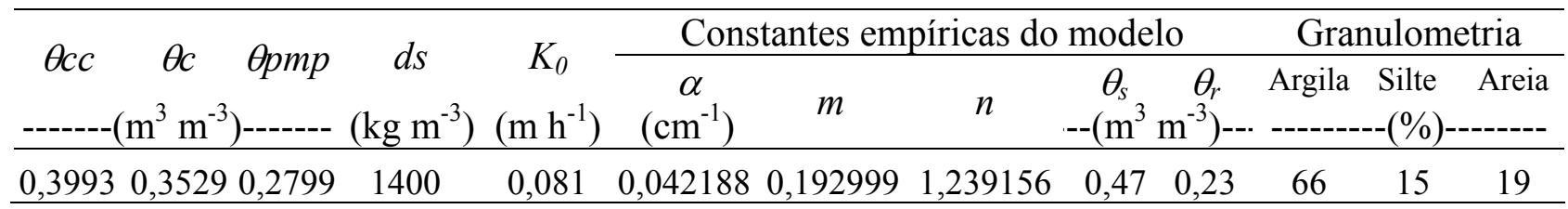

$\theta c c$ - umidade do solo à capacidade de campo; $\theta c$ - umidade crítica do solo; $\theta p m p$ - umidade do solo no ponto de murchamento permanente; $d s$ - densidade do solo; $K_{0}$ - condutividade hidráulica do solo saturado; $\theta_{s}$ - umidade do solo saturado; $\theta_{r}$ - umidade residual do solo.

Foram também determinadas a capacidade de água disponível no solo ( $C A D$, em $\mathrm{mm})$, a água facilmente disponível no solo $(A F D$, em $\mathrm{mm})$ e a reserva de água disponível crítica do solo ( $R A D c$, em $\mathrm{mm})$, de acordo com as expressões:

$$
\begin{aligned}
& \mathrm{CAD}=(\theta \mathrm{cc}-\theta \mathrm{pmp}) \mathrm{Z} \\
& \mathrm{AFD}=(\theta \mathrm{cc}-\theta \mathrm{c}) \mathrm{Z} \\
& \mathrm{RADc}=\mathrm{CAD}-\mathrm{AFD}
\end{aligned}
$$

em que,

$\theta \mathrm{cc}$ - umidade do solo à capacidade de campo para o potencial mátrico de $-10 \mathrm{kPa}, \mathrm{m}^{3} \mathrm{~m}^{-3}$;

$\theta \mathrm{c}$ - umidade crítica do solo correspondente ao valor do potencial mátrico crítico da água no solo $\left(\Psi \mathrm{m}_{\mathrm{c}}\right)$ de $-40 \mathrm{kPa}$ para a cultura do feijoeiro (SILVEIRA \& STONE, 1994), $\mathrm{m}^{3} \mathrm{~m}^{-3}$;

Өpmp - umidade do solo no ponto de murchamento permanente para o potencial mátrico de $1.500 \mathrm{kPa}, \mathrm{m}^{3} \mathrm{~m}^{-3}$, e

$\mathrm{Z}$ - profundidade, $400 \mathrm{~mm}$. 
O momento definido como o de irrigação, tanto para Tens quanto para TCA, foi aquele em que a umidade atual do solo estimada $(\theta a)$ atingiu valor igual ou menor ao do $\theta c$, considerando, no dia previsto em função da variação diária da $\theta a$ ou nos três dias posteriores, se a probabilidade de ocorrência de chuva igual ou maior do que a $A F D$ fosse maior ou igual a $70 \%$. Quando isso aconteceu, verificou-se a confirmação ou não desse evento no dia previsto e com qual quantidade. Caso a previsão não fosse efetivada, acompanhava-se a previsão do dia seguinte e dos dois dias posteriores a esse, se necessário. Não havendo a ocorrência de chuva, procedia-se à irrigação com a lâmina correspondente à água disponível consumida do solo até o dia da irrigação $(A D C i)$.

Os dados utilizados de previsão de chuva para Jaboticabal - SP, foram obtidos diariamente pela manhã, por correio eletrônico (ctmail@climatempo.net ou www.climatempo.com.br).

Nas parcelas dos tratamentos Tens, o manejo da irrigação foi baseado no $\Psi m_{c}$ médio entre os tensiômetros de decisão do momento de irrigação, de $0,15 \mathrm{~m}$ de profundidade, conforme preconizado por SILVEIRA \& STONE (1994), para cada um dos sistemas de preparo do solo (PC e $\mathrm{PD})$. A lâmina de irrigação ou água disponível consumida até o dia da irrigação $\left(A D C i_{(T e n s)}\right)$, em $\mathrm{mm}$, foi calculada conforme a expressão:

$$
\mathrm{ADCi}_{(\mathrm{Tens})}=(\theta \mathrm{cc}-\theta \mathrm{ai}) \mathrm{Z} ; \theta \mathrm{ai} \leq \theta \mathrm{c} ; \operatorname{ADCi}_{(\mathrm{Tens})} \geq \operatorname{AFD}(18,6 \mathrm{~mm})
$$

em que,

Өai - umidade atual do solo no momento da irrigação, $\mathrm{m}^{3} \mathrm{~m}^{-3}$.

O manejo da irrigação pelo balanço hídrico climatológico simplificado considerou o balanço em 24 horas entre a evapotranspiração da cultura $(E T c)$, estimada pelo método do tanque Classe A, segundo ALLEN et al. (1998a; b), e a chuva efetiva $(P e, \mathrm{~mm})$ incorporada ao solo na camada de 0 a $0,40 \mathrm{~m}$ de profundidade. Assim, o cálculo da lâmina líquida de irrigação ou $A D C i_{(T C A)}$, tomada como referência para a lâmina de irrigação a ser aplicada com o pivô central, foi obtido da seguinte expressão do balanço hídrico climatológico simplificado:

$$
\mathrm{ADCi}_{(\mathrm{TCA})}=\sum_{\mathrm{ti}}^{\mathrm{tj}}(\mathrm{ETc}-\mathrm{Pe}) \geq 0 ; \operatorname{ADCi}_{(\mathrm{TCA})} \geq \operatorname{AFD}(18,6 \mathrm{~mm}) ;
$$

em que,

(tj-ti) - duração do intervalo entre duas irrigações consecutivas, dias, e

Pe - chuva efetiva diária $(24 \mathrm{~h}), \mathrm{mm}$, considerada como segue:

se $\mathrm{P} \geq \mathrm{ADCa} ; \mathrm{Pe}=\mathrm{ADCa}$;

se $\mathrm{P}<\mathrm{ADCa} ; \mathrm{Pe}=\mathrm{P}$

sendo,

P - chuva total diária (24 h) coletada em um pluviômetro tipo "Ville de Paris", mm, e

ADCa - água disponível consumida atual do solo (mm), sendo calculada por:

$\mathrm{ADCa}=(\theta \mathrm{cc}-\theta \mathrm{a}) \mathrm{Z}$

A ETc ( $\left.\mathrm{mm} \mathrm{dia}^{-1}\right)$ foi estimada de acordo com a expressão:

$\mathrm{ETc}=\mathrm{ECA} \mathrm{Kp} \mathrm{Kc}$

em que,

ECA - evaporação medida no tanque Classe A, $\mathrm{mm} \mathrm{dia}^{-1}$;

$\mathrm{Kp}$ - coeficiente de tanque (adimensional) cujos valores foram calculados baseados em ALLEN et al. (1998a), e

Kc - coeficiente de cultura simplificado (adimensional), estimado diariamente para o feijoeiro, de acordo com ALLEN et al. (1998b).

A lâmina de irrigação efetivamente aplicada em cada irrigação foi baseada na lâmina média obtida imediatamente após as irrigações, da medição das lâminas coletadas por três pluviômetros 
instalados a 0,50 $\mathrm{m}$ do solo (acima do dossel da cultura), na diagonal de cada parcela experimental, resultando em 27 pluviômetros por tratamento e 108 pluviômetros em toda a área experimental.

Os valores médios diários de potencial mátrico $\left(\Psi_{m}\right)$ para as profundidades de $0,10 \mathrm{~m} ; 0,15 \mathrm{~m}$; $0,20 \mathrm{~m}, 0,30 \mathrm{~m}$ e $0,50 \mathrm{~m}$ obtidos dos tensiometros, em todos os tratamentos, foram transformados em umidade volumétrica média diária para a camada de 0 a $0,40 \mathrm{~m}$ de profundidade por meio da expressão (1).

Também foram determinadas a reserva de água disponível atual do solo $(R A D a)$ e a reserva de água disponível limite para a cultura $(R A D l)$, que foram transformadas em frações da $C A D$, de acordo com as expressões:

$$
\begin{aligned}
& \mathrm{RADa}=1-\frac{\mathrm{ADCa}}{\mathrm{CAD}} 100 \\
& \mathrm{RADl}=(1-\mathrm{p}) \mathrm{CAD}
\end{aligned}
$$

em que,

p - fator de depleção de água no solo ajustado em função da ETc diária estimada pelo método do tanque Classe A, calculado segundo a expressão (ALLEN et al., 1998b):

$$
\mathrm{p}=\mathrm{p}_{\mathrm{tab}}+0,04(5-\mathrm{ETc})
$$

em que,

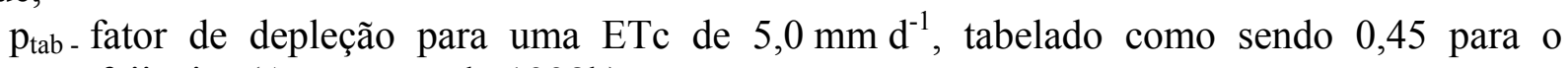
feijoeiro (ALLEN et al., 1998b).

Ao final do ciclo da cultura, foram avaliados os seguintes componentes de produtividade: número médio de vagens produtivas por planta, número médio de grãos por vagem, massa média de 1.000 grãos (cinco amostras por parcela) e produtividade de grãos (12\% de umidade).

Aplicando-se o método do perfil instantâneo para a camada de solo de 0 a 0,40 m de profundidade e determinando os componentes do balanço hídrico do solo, conforme metodologia descrita por LIBARDI (2005), foi estimada como componente residual da equação do balanço a evapotranspiração real média $\left(\mathrm{ETr}-\mathrm{mm} \mathrm{d}^{-1}\right)$ do ciclo da cultura (94 dias) para cada tratamento, considerando períodos médios de dez dias. Foi também calculada a eficiência de uso de água pela cultura (EUAC - $\mathrm{kg} \mathrm{m}^{-3}$ ), definida como eficiência de produção, ou seja, a massa de grãos produzida para cada unidade de volume de água consumida por evapotranspiração da cultura durante todo o seu ciclo (TENNAKOON \& HULUGALLE, 2006). A EUAC foi calculada por meio da razão entre a produtividade média de grãos $\left(\mathrm{kg} \mathrm{m}^{-2}\right)$ e o volume total de água aplicado por irrigação durante os 94 dias do ciclo da cultura, baseado na ETr média $\left(\mathrm{mm} \mathrm{d}^{-1}\right)$.

\section{RESULTADOS E DISCUSSÃO}

Os tratamentos de manejo de irrigação TCA resultaram, no geral, em valores de potenciais mátricos maiores do que nos de Tens (Figura 1). Em termos quantitativos, isso representa maior disponibilidade hídrica na zona radicular das plantas sob TCA, resultando na manutenção de maiores valores médios de RADa (Figura 2), embora ambos tenham-se mantido acima da RAD1.

$\mathrm{O}$ tratamento $\mathrm{PD}-\mathrm{Tens}$ foi o que apresentou os menores valores de potencial mátrico, com média de $-41,0 \mathrm{kPa} \pm 10,2 \mathrm{kPa}$, seguido pelo PC-Tens com $-37,3 \mathrm{kPa} \pm 6,5 \mathrm{kPa}$. Os tratamentos TCA foram os que apresentaram maiores valores de potencial mátrico; a média do PC-TCA foi de $-26,3 \mathrm{kPa} \pm 8,7 \mathrm{kPa}$ e a do PD-TCA de $-19,0 \mathrm{kPa} \pm 6,6 \mathrm{kPa}$. Isso evidencia que o controle da irrigação, tomando como referenciais o potencial mátrico de $-40,0 \mathrm{kPa}$ no tensiômetro-controle (0,15 $\mathrm{m}$ de profundidade) e a profundidade efetiva de $0,40 \mathrm{~m}$, manteve, em média, condições hídricas no solo acima do potencial mátrico crítico, à exceção do PD-Tens. 


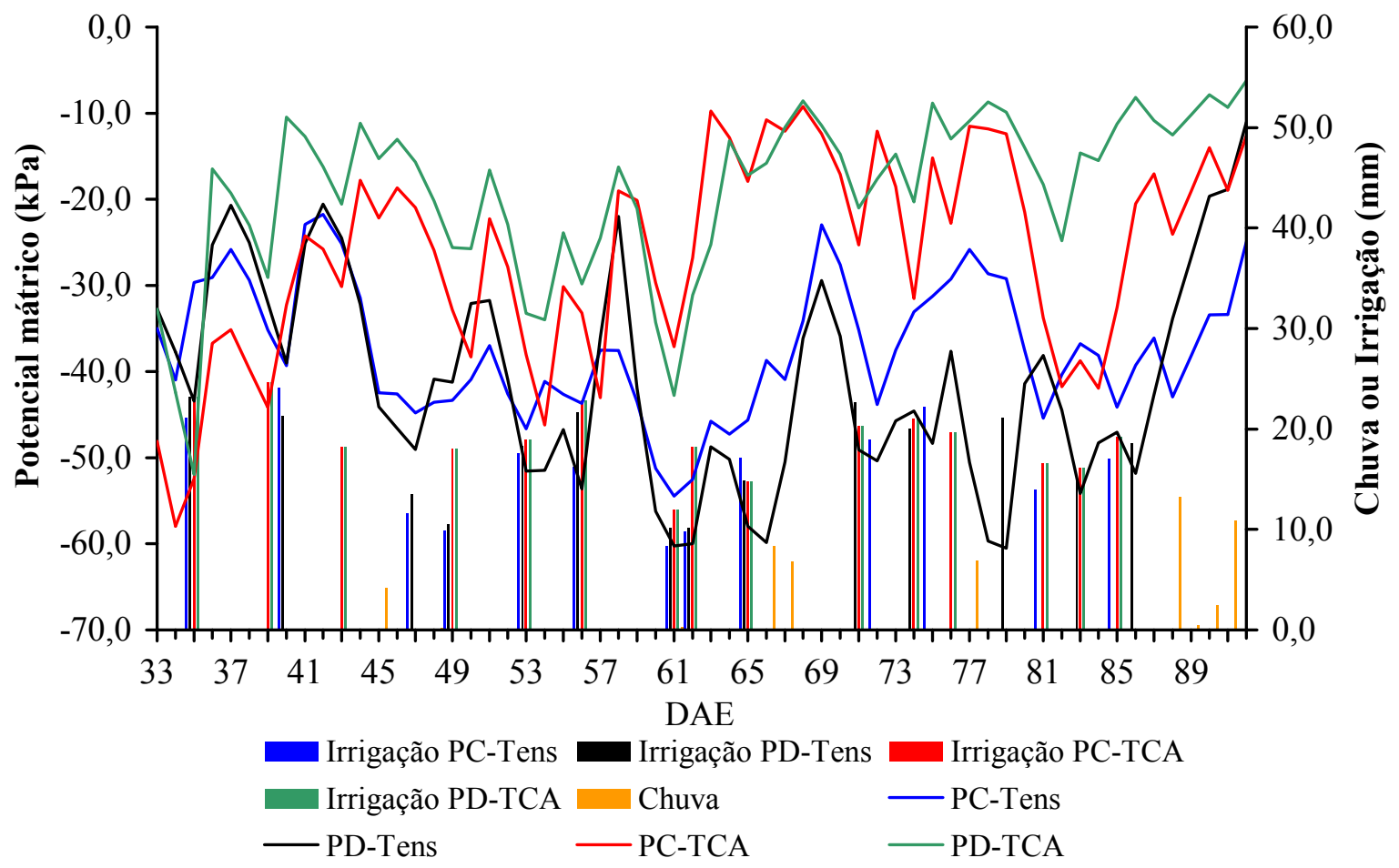

FIGURA 1. Variação diária do potencial mátrico médio do solo na camada de 0 a $0,40 \mathrm{~m}$ de profundidade ( $\mathrm{kPa}$ - linhas) e chuva ou irrigação ( $\mathrm{mm}$ - barras verticais) ocorridas dos 33 aos 92 dias após a emergência (DAE). Daily variation of the soil matrix potential average in the layer from 0 to $0.40 \mathrm{~m}$ of depth ( $\mathrm{kPa}$ - lines) and rain or irrigation (mm - vertical bars) occurred between 33 and 92 days after the seedlings emergency (DAE).

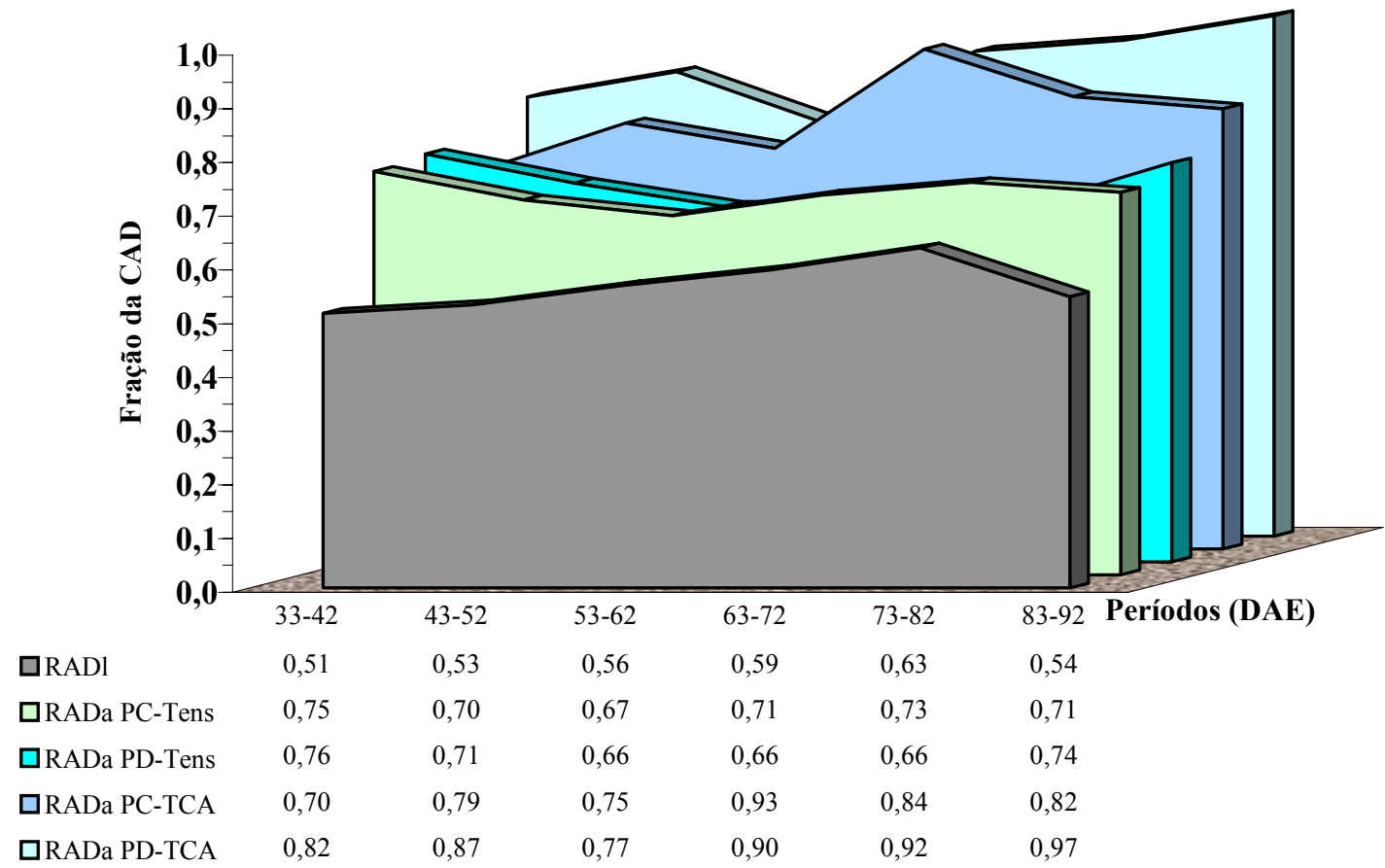

FIGURA 2. Reserva de água disponível limite (RADl) e reserva atual de água disponível (RADa) como fração da capacidade de água disponível do solo (Fração da CAD) até a profundidade de $0,40 \mathrm{~m}$. Available water reserves limit $(\boldsymbol{R} A \boldsymbol{D} \boldsymbol{l})$ and reserves of actual available water $(R A D a)$ of the soil as fraction of the available water capacity (CAD fraction) to the $0.40 \mathrm{~m}$ of soil depth. 
Verifica-se que o comportamento real da água no solo, sensoriado pelos tensiômetros instalados na camada de 0 a 0,40 m de profundidade (Figura 1), não correspondeu, exatamente, ao estimado pelo tanque Classe A, uma vez que a tensão de água no solo permaneceu, na sua grande maioria, próxima à da capacidade de campo $(-10 \mathrm{kPa})$, diferindo do verificado nos tratamentos Tens, que apresentaram maiores variações.

Quanto aos componentes de produtividade, houve interação significativa entre sistemas de manejo do solo e de irrigação, exceto para número médio de grãos por vagem (Tabela 2). Com exceção do estande final de plantas, nos demais componentes de produtividade, o TCA foi superior ao Tens apenas quando o preparo do solo foi feito com o sistema convencional (PC).

O manejo de irrigação TCA manteve condições de menor variabilidade de potencial mátrico no solo durante todo o ciclo da cultura (Figura 1) e, conseqüentemente, valores médios decendiais da $R A D a$ maiores do que os do Tens para ambos os sistemas de manejo do solo, PC e PD (Figura 2). Enquanto, no PC, essa diferença do TCA para o Tens se traduziu em diferença significativa de produtividade de grãos $(\mathrm{P}<0,05)$ em favor do TCA, no $\mathrm{PD}$ não houve diferença de produtividade $(\mathrm{P}>0,05)$ entre os manejos de irrigação (Tabela 2). Isso indica que o sistema PD de manejo do solo foi menos suscetível do que o PC à variabilidade hídrica no solo decorrente das diferenças de armazenamento de água na zona radicular proporcionadas pelos sistemas de manejo de irrigação ao longo do ciclo da cultura.

TABELA 2. Componentes de produtividade da cultura do feijoeiro. Productivity components of dry bean.

\begin{tabular}{|c|c|c|c|}
\hline \multirow{2}{*}{ Sistemas de Manejo } & \multicolumn{3}{|c|}{ Manejo da Irrigação } \\
\hline & Tens $^{1}$ & & $\mathrm{TCA}^{1}$ \\
\hline & \multicolumn{3}{|c|}{ Número médio de vagens por planta } \\
\hline $\mathrm{PC}$ & $6,47 \mathrm{Ab}$ & & 9,09 Aa \\
\hline \multirow[t]{2}{*}{ PD } & $6,53 \mathrm{Aa}$ & & $6,77 \mathrm{Ba}$ \\
\hline & \multicolumn{3}{|c|}{ Estande final de plantas (planta $\mathrm{m}^{-2}$ ) } \\
\hline $\mathrm{PC}$ & $30,99 \mathrm{Ba}$ & & $35,96 \mathrm{Aa}$ \\
\hline \multirow[t]{2}{*}{ PD } & $41,66 \mathrm{Aa}$ & & $40,48 \mathrm{Aa}$ \\
\hline & \multicolumn{3}{|c|}{ Massa de 1.000 grãos $(\mathrm{g})$} \\
\hline $\mathrm{PC}$ & $263,57 \mathrm{Ab}$ & & $275,46 \mathrm{Aa}$ \\
\hline \multirow[t]{2}{*}{$\mathrm{PD}$} & $269,09 \mathrm{Aa}$ & & $262,21 \mathrm{Ba}$ \\
\hline & \multicolumn{3}{|c|}{ Produtividade de grãos $\left(\mathrm{kg} \mathrm{ha}^{-1}\right)$} \\
\hline $\mathrm{PC}$ & $1.865,6 \mathrm{Bb}$ & & $3.394,6 \mathrm{Aa}$ \\
\hline \multirow[t]{3}{*}{$\mathrm{PD}$} & $2.805,8 \mathrm{Aa}$ & & $2.755,0 \mathrm{Ba}$ \\
\hline & \multicolumn{3}{|c|}{ Número médio de grãos por vagem } \\
\hline & Tens & TCA & Média $^{1}$ \\
\hline $\mathrm{PC}$ & 3,46 & 3,84 & $3,65 \mathrm{~A}$ \\
\hline PD & 3,79 & 3,83 & $3,81 \mathrm{~A}$ \\
\hline Média & $3,62 \mathrm{~b}$ & $3,83 \mathrm{a}$ & \\
\hline \multicolumn{4}{|c|}{$\begin{array}{l}\text { Médias seguidas de letras distintas, maiúsculas nas colunas e minúsculas nas linhas, diferem entre si, pelo teste d } \\
\text { Tukey }(\mathrm{P}<0,05) \text {. }\end{array}$} \\
\hline \multicolumn{4}{|c|}{$\begin{array}{l}\text { Dentro de cada sistema de manejo de irrigação, verifica-se que, no Tens, o PD foi superior ao } \\
\text { PC }(\mathrm{P}<0,05) \text { apenas para os componentes estande final de plantas e produtividade de grãos, não } \\
\text { havendo diferença entre PC e PD }(\mathrm{P}>0,05) \text { para os demais componentes (Tabela } 2) \text {. Em relação ao } \\
\text { TCA, o PD foi inferior ao PC nos componentes de produtividade }(\mathrm{P}<0,05) \text {, com exceção do } \\
\text { estande final de plantas, sendo superado pelo PC na produtividade de grãos em cerca de } 21 \% \text {. } \\
\text { Portanto, os resultados evidenciam que, no PC, as variações do potencial e do conteúdo de água } \\
\text { armazenado no solo ao longo do ciclo da cultura do feijoeiro devem ser menores para que a } \\
\text { produtividade de grãos seja elevada. }\end{array}$} \\
\hline
\end{tabular}


Analisando os resultados de EUAC e ETr (Tabela 3), verifica-se que, em média, a ETr foi maior no manejo de irrigação TCA do que no Tens, assim como a produtividade média de grãos (Tabela 2) no TCA $\left(3.074,8 \mathrm{~kg} \mathrm{ha}^{-1}\right)$ também foi maior do que no Tens $\left(2.335,7 \mathrm{~kg} \mathrm{ha}^{-1}\right)$, resultando em maior EUAC para os tratamentos TCA. Isso indica que a maior disponibilidade de água no solo, ao longo do ciclo da cultura (Figuras 1 e 2), proporcionada pelo manejo de irrigação baseado no TCA, levou a aumento relativo da evapotranspiração das plantas (13\%), menos do que proporcional ao da produtividade de grãos (35\%), o que resultou no aumento da EUAC neste tratamento.

TABELA 3. Evapotranspiração real média do ciclo (ETr) e eficiência de uso de água pela cultura do feijoeiro (EUAC). Real evapotranspiration as average of the dry bean cycle (ETr) and crop water use efficiency (EUAC).

\begin{tabular}{ccccccc}
\hline \multirow{2}{*}{ Tratamentos } & \multicolumn{2}{c}{ Tens } & \multicolumn{2}{c}{ TCA } & \multicolumn{2}{c}{ Média } \\
\cline { 2 - 7 } & $\begin{array}{c}\text { ETr } \\
\left(\mathrm{mm} \mathrm{d}^{-1}\right)\end{array}$ & $\begin{array}{c}\text { EUAC } \\
\left(\mathrm{kg} \mathrm{m}^{-3}\right)\end{array}$ & $\begin{array}{c}\text { ETr } \\
\left(\mathrm{mm} \mathrm{d}^{-1}\right)\end{array}$ & $\begin{array}{c}\text { EUAC } \\
\left(\mathrm{kg} \mathrm{m}^{-3}\right)\end{array}$ & $\begin{array}{c}\text { ETr } \\
\left(\mathrm{mm} \mathrm{d}^{-1}\right)\end{array}$ & $\begin{array}{c}\text { EUAC } \\
\left(\mathrm{kg} \mathrm{m}^{-3}\right)\end{array}$ \\
\hline PC & 3,97 & 0,52 & 4,82 & 0,77 & 4,40 & 0,64 \\
PD & 4,43 & 0,69 & 4,66 & 0,65 & 4,54 & 0,67 \\
Média & 4,20 & 0,60 & 4,75 & 0,71 & 4,47 & 0,66 \\
\hline
\end{tabular}

Avaliando-se o efeito dos sistemas de manejo do solo, verifica-se acréscimo de apenas 3\% na ETr do PD em relação ao PC, o que resultou também em acréscimo relativo de 5\% na EUAC. Essa pequena diferença, embora positiva, pode ser explicada pelo pouco tempo de aplicação do PD na área (2 anos).

Dentro do tratamento PC verificou-se maior variabilidade dos valores de ETr entre os manejos de irrigação (Tabela 3), que foi $21 \%$ maior no PC-TCA do que no PC-Tens, enquanto, no PD, a diferença entre Tens e TCA foi de apenas 5\% a favor do PD-TCA. Os valores de EUAC evidenciam a maior variabilidade do PC, uma vez que, sob manejo com tensiometria (Tens), esse sistema de cultivo resultou na menor EUAC, enquanto sob TCA foi a maior eficiência de uso de água entre todos os tratamentos. O PC-TCA superou em $48 \%$ a EUAC do PD-Tens e, no PD, a variação na EUAC foi de apenas $6 \%$ a favor do PD-Tens.

$\mathrm{O}$ fato de a cultura do feijoeiro ter expressado melhores produtividades nas combinações PCTCA e PD-Tens, sugere que a escolha do método de manejo de irrigação deve ser baseada, também, no sistema de manejo do solo, uma vez que as condições físico-hídricas do solo são diretamente afetadas pelas diferentes formas de seu manejo.

O solo no plantio convencional, após o seu preparo, além de ficar praticamente desprovido de cobertura morta, apresenta mudanças nas suas condições físico-hídricas (porosidade e densidade, principalmente), o que pode resultar em menor capacidade de retenção e redistribuição de água e mudanças na interação solo-raiz. Diante de tal situação, o suprimento de água à cultura deve ser realizado de maneira mais abundante, uma vez que, segundo REICHARDT \& TIM (2004), a quantidade de água absorvida do solo pelas plantas não é somente função do seu potencial, mas, também, da habilidade das raízes em absorver a água do solo com que estão em contato, bem como das propriedades do solo no fornecimento e na transmissão dessa água às raízes, em uma proporção que satisfaça as exigências da transpiração.

Avaliando os sistemas de manejo do solo PC e PD na cultura do milho, SILVA et al. (2004a) concluíram que o PD proporcionou condições físicas no solo mais favoráveis às plantas, comparado ao sistema PC.

Diante disso, a menor ETr média (Tabela 3) e a menor produtividade do PC-Tens (Tabela 2) podem indicar que o manejo da irrigação por tensiometria, conjugado com o manejo convencional de preparo do solo, resultou em condições mais restritivas no solo ao fluxo de água deste para as raízes, afetando em maior grau do que nos demais tratamentos combinados a evapotranspiração da 
cultura, mesmo que a reserva atual de água disponível no solo $(R A D a)$, nesse tratamento, tenha-se mantido superior à limite $(R A D l)$ durante todo o ciclo da cultura (Figura 2).

O TCA estimou, em média, lâmina total de irrigação $21,7 \%$ maior do que a estimada pelo Tens, enquanto LOPES et al. (2004), no primeiro ano de plantio direto, obtiveram $15 \%$ de redução na lâmina total aplicada, baseada no Tens, em relação à aplicada com base no TCA.

Dentro do PD foi $17,2 \%$ maior a lâmina estimada pelo TCA e, no PC, foi $26,6 \%$, indicando que, no PD, houve economia de água quando o manejo de irrigação foi o de tensiometria. Já em PC, evidenciou-se a dependência por lâminas de irrigação maiores para que produtividade elevada fosse obtida.

\section{CONCLUSÕES}

A combinação de manejo de irrigação utilizando o tanque Classe A com o sistema convencional de preparo do solo resultou em maior evapotranspiração média, maior produtividade de grãos e maior eficiência de uso de água pela cultura.

O manejo de irrigação baseado no método do tanque Classe A propiciou condições físicohidricas no sistema solo-planta que resultaram em maior eficiência de uso da água pela cultura do que o manejo de irrigação por tensiometria.

O sistema plantio direto foi menos suscetível do que o sistema de preparo convencional às variações hídricas no solo decorrentes dos sistemas de manejo de irrigação empregados, refletindo em menor variação na produtividade de grãos.

\section{REFERÊNCIAS}

ABNT. ASSOCIAÇÃO BRASILEIRA DE NORMAS TÉCNICAS. Projeto de norma 04:015.08008: Métodos de ensaio para determinação da uniformidade de distribuição de água em equipamentos de irrigação mecanizada (pivô central e lateral móvel), providos de emissores fixos ou rotativos. São Paulo, 1998. 13 p.

ALLEN, R.G.; PEREIRA, L.S.; RAES, D.; SMITH, M. ETc - single crop coefficient (Kc). In: . Crop evapotranspiration: guidelines for computing crop requirements. Roma: FAO, 1998a. p.103-34. (Irrigation and Drainage, 56).

ALLEN, R.G.; PEREIRA, L.S.; RAES, D.; SMITH, M. ETc under soil water stress conditions. In: . Crop evapotranspiration: guidelines for computing crop requirements. Roma: FAO, 1998b. p.161-82. (Irrigation and Drainage, 56).

BANZATTO, D.A.; KRONKA, S.N. Experimentação agrícola. Jaboticabal: FUNEP, 1989. 247 p.

DOURADO NETO, D.; FANCELLI, A.L. Produção do feijão. Guaíba: Agropecuária, 2000. $385 \mathrm{p}$.

EMBRAPA. EMPRESA BRASILEIRA DE PESQUISA AGROPECUÁRIA. Sistema brasileiro de classificação de solos. Rio de Janeiro, 1999. $412 \mathrm{p}$.

ESTAÇÃO AGROCLIMATOLÓGICA. Normais Climatológicas FCAV/UNESP. Disponível em: www.fcav.unesp.br/departamentos/exatas/estacao/normal.html. Acesso em: 30 mar. 2003.

GENUCHTEN, M.Th. Van. A closed form equation for predicting the hydraulic conductivity of insaturated soils. Soil Science Society of American Journal, Madison, v.41, p.892-8, 1980.

KLUTHCOUSKI, J.; FANCELLI, A.L.; DOURADO NETO, D.; RIBEIRO, C.M.; FERRARO, L.A. Manejo do solo e o rendimento de soja, milho, feijão e arroz em plantio direto. Scientia Agrícola, Piracicaba, v.57, n.1, p.97-104, 2000.

LIBARDI, P.L. Dinâmica da água no solo. São Paulo: Edusp, 2005. 335 p. 
LOPES, A.S.; PAVANI, L.C.; CORA, J.E.; ZANINI, J.R.; MIRANDA, H.A. Manejo da irrigação (tensiometria e balanço hídrico climatológico) para a cultura do feijoeiro em sistemas de cultivo direto e convencional. Engenharia Agrícola, Jaboticabal, v.24, n.1, p.89-100, 2004.

OLIVEIRA, L.F.C.; NASCIMENTO, J.L.; STONE, L.F. Demanda total de água do feijoeiro nos sistemas de plantio convencional e direto. In: CONGRESSO BRASILEIRO DE ENGENHARIA AGRÍCOLA, 29., 2000, Fortaleza. Anais... Fortaleza: SBEA, 2000. 1 CD-ROM.

PIRES, R.C.M.; SAKAI, E.; ARRUDA, F.B.; FOLEGATTI, M.V. Necessidades hídricas das culturas e manejo de irrigação In: MIRANDA, J.H.; PIRES, R.C.M. Irrigação. Piracicaba: SBEA, 2001. v.1, p.121-94. (Série Engenharia Agrícola).

REICHARDT, K.; TIMM, L.C. Solo, planta e atmosfera - conceitos, processos e aplicações. Barueri: Manole, 2004. 478 p.

SILVA, A.P., IMHOFF, S.; KAY, B. Plant response to mechanical resistance and air-filled porosity of soils under conventional and no-tillage system. Scientia Agricola, Piracicaba, v.61, n.4, p.451-6, 2004a.

SILVA, M.G.; ARF, O.; SA, M.E.; RODRIGUES, R.A.F.; BUZETTI, S. Nitrogen fertilization and soil management of winter common bean crop. Scientia Agrícola, Piracicaba, v.61, n.3, p.307-12, $2004 b$.

SILVEIRA, P.M.; STONE, L.F. Manejo da irrigação do feijoeiro: uso do tensiômetro e avaliação do desempenho do pivô central. Brasília: EMBRAPA, 1994. 46 p. (Circular Técnica, 27).

SILVEIRA, P.M.; STONE, L.F. Profundidade de amostragem do solo sob plantio direto para avaliação de características químicas. Revista Brasileira de Ciência do Solo, Viçosa, v.26, n.1, p.157$62,2002$.

STONE, L.F.; SILVEIRA, P.M. Efeito do sistema de preparo na compactação do solo, disponibilidade hídrica e comportamento do feijoeiro. Pesquisa Agropecuária Brasileira, Brasília, v.34, n.1, p.83-91, 1999.

TENNAKOON, S.B.; HULUGALLE, N.R. Impact of crop rotation and minimum tillage on water use efficiency of irrigated cotton in a Vertisol. Irrigation Science, Berlin, v.25, n.1, p.45-52, 2006. 